Article

\title{
An Optimization Model for Large-Scale Wind Power Grid Connection Considering Demand Response and Energy Storage Systems
}

\section{Zhongfu Tan ${ }^{1, \dagger}$, Huanhuan $\mathrm{Li}^{1, \dagger, *}$, Liwei Ju ${ }^{1, \dagger}$ and Yihang Song ${ }^{2, \dagger}$}

1 Institute of Energy Economics and Environment, North China Electric Power University, 2 Beinong Road, Huilongguan Town, Changping District, Beijing 102206, China;

E-Mails: zhongfu_Tan@ncepu.edu.cn (Z.T.); liwei_Ju@ncepu.edu.cn (L.J.)

2 Electric Power Research Institute, China South Power Grid, Guangzhou 510080, China; E-Mail: yihang_song@ncepu.edu.cn

$\dagger$ These authors contributed equally to this work.

* Author to whom correspondence should be addressed; E-Mail: lihuanhuan@ ncepu.edu.cn; Fax: +86-10-5196-3749.

External Editor: Frede Blaabjerg

Received: 29 August 2014; in revised form: 5 October 2014 / Accepted: 28 October 2014 / Published: 13 November 2014

\begin{abstract}
To reduce the influence of wind power output uncertainty on power system stability, demand response (DRPs) and energy storage systems (ESSs) are introduced while solving scheduling optimization problems. To simulate wind power scenarios, this paper uses Latin Hypercube Sampling (LHS) to generate the initial scenario set and constructs a scenario reduction strategy based on Kantorovich distance. Since DRPs and ESSs can influence the distribution of demand load, this paper constructs a joint scheduling optimization model for wind power, ESSs and DRPs under the objective of minimizing total coal cost, and constraints of power demand and supply balance, users' demand elasticity, thermal units' startup-shutdown, thermal units' output power climbing and wind power backup service. To analyze the influences of ESSs and DRPs on system wind power consumption capacity, example simulation is made in a 10 thermal units system with a $1000 \mathrm{MW}$ wind farm and $400 \mathrm{MW}$ energy storage systems under four simulation scenarios. The simulation results show that the introduction of DRPs and ESSs could promote system wind power consumption capacity with significantly economic and environment benefits,
\end{abstract}


which include less coal consumption and less pollutant emission; and the optimization effect reaches the optimum when DRPs and ESSs are both introduced.

Keywords: wind power consumption; demand response; energy storage systems; Unit combination; scheduling optimization

\section{Introduction}

China's wind power industry has been in rapid development since 2005. By the end of 2013, the total installed wind power capacity reached $94.41 \mathrm{GW}$, ranking first in the world. However, large-scale installed wind power capacity results in the problem of abandoned wind power. In 2013, the average equivalent utilization hour of wind power in some Chinese provinces was only 1,400 h, and the total abandoned wind power reached $20 \mathrm{TW} \cdot \mathrm{h}$. Since wind turbines' power generation efficiency cannot be guaranteed, generation companies' investment enthusiasm in wind power is gradually decreasing. The current situation is not beneficial to the wind power industry's sustainable development [1].

In China, the wind power consumption problem remains the main bottleneck of wind power's large-scale development. The reasons for abandoned wind power are two-fold. On the one hand, wind power is intermittent and unstable [2], increasing the difficulty of system scheduling problems. On the other hand, wind power output is anti-load distributed [3-5]. China's wind resources are mainly distributed in the "Three north-areas" which are far away from load demand centers, and local load demand cannot meet the consumption requirements [6,7]. Besides, mismatched grid infrastructures and uncoordinated interest relationships of wind power, grid enterprise and thermal power also influence wind power grid connection $[8,9]$.

Current, literature about wind power consumption problems concentrates on two aspects: local consumption schemes and wind power delivery. Since wind power output is uncertain, thermal power, hydro power or other traditional power sources are required to provide backup service for wind power delivery [10-12]. However, general wind power delivery has a series of constraints, such as power transmission capacity, transmission power stability, load demand and other factors [13,14]. Local consumption methods include building pumped storage power station, developing electric vehicles, utilizing energy storage systems, etc. [15-20]. Energy storage systems (ESSs) can achieve peak shifting, decrease the influence of wind power uncertainty and improve wind power utilization rate. Therefore, ESSs have great application potential for wind power consumption problems.

There are four major methods to improve systems' wind power consumption capacity, including improving system adjustment ability [21], improving power grid transmission capacity [22,23], improving wind power grid connection technology performance [24,25] and improving wind power scheduling operation levels [26,27]. Improving wind power scheduling operation level is the key to solving wind power consumption problems [8]. The above literatures are mainly focused on optimizing wind power consumption problems from the power generation side. Considering time-of-use price (TOU price) and ESSs both have the capacity to influence demand load distribution, this paper tries to optimize the power system scheduling problem from power generation side and load demand side, which means optimizing units' combined output structure and demand load distribution at the same time. This paper introduces 
DRSs and ESSs to the wind power consumption optimization model, and optimizes real-time outputs of thermal units and wind turbines, real-time charging-discharging behavior of energy storage systems to thus achieve the system's maximum energy-saving benefits.

The rest of the paper is organized as follows: Section 2 presents the demand response model. The model divides $24 \mathrm{~h}$ of one day into peak, flat and valley load periods according to their load demands and calculates load variation amounts according to the elasticity coefficients. Section 3 presents the energy storage system's charging and discharging model. The model takes the energy storage system's capacity limitation, power limitations, and energy consumption coefficients as the constraints. In Section 4, Latin Hypercube Sampling (LHS) and Kantorovich distance method are used, respectively, to simulate wind power output scenarios and construct a reduction strategy scenario. Section 5 builds a power generation scheduling optimization model with wind power; Section 6 builds another model considering the influences of ESSs and DRPs. Section 7 divides thermal units' power generation coal consumption function into segments to transform the quadratic function into a linear function, and deals with the multiplication of two binary variables in the objective functions to simplify the calculation. In Section 8 we perform a case study and simulation to compare the influences of demand response and energy storage systems on a power grid's wind power consumption capacity. Section 9 highlights the main conclusions of the paper.

\section{Demand Response Model}

Demand side management (DSM) means controlling user-behavior by changing their electric use habits, improving terminal electricity efficiency and other measures. DSM could decrease total electric consumption while guaranteeing meeting users' demand. There are many types of DSM mechanisms, for example Rate basing, Energy-saving benefit sharing, RDM Plus and so on [28]. This paper chooses time-of-use price (TOU price) to study its influence on power efficiency. With the influence of TOU price, users would decrease load demand in peak load periods and transfer their demand into flat or valley load periods, making the demand load curve become smoother.

Users Load demand should be calculated by its real load demand and corresponding line-loss rate. The total load demand for all users should be a summation of all types and voltage levels users' load demands. Therefore, total demand load before implementing the TOU price $G_{t}^{0}$ could be calculated by Equation (1):

$$
G_{t}^{0}=\sum_{i=1}^{I} \sum_{k=1}^{K} L_{i k t}^{0} /\left(1-l_{k}\right)
$$

wherein $I$ is user type number; $i$ is the index for time, $i=1,2, \ldots, I ; K$ is voltage level number; $k$ is the index for voltage level, $k=1,2, \ldots, K$; $T$ is time length; $t$ is the index of time, $t=1,2, \ldots, T ; L_{i k t}^{0}$ is the load demand of user $i$ in voltage level $k$ without TOU price; $I$ is the number of user types; $K$ is the number of voltage levels; $l_{k}$ is the line-loss rate of voltage level $k, l_{k} \in(0,1)$.

Demand load after implementing TOU price is:

$$
L_{i k t}=L_{i k t}^{0}+\Delta L_{i k t}
$$

wherein $L_{i k t}$ is the load demand of user $i$ in voltage level $k$ with TOU price; $\Delta L_{i k t}$ is the variation amount of load demand.

We divide $24 \mathrm{~h}$ into peak, flat and valley load periods according to total demand load $G_{t}^{0}$. When TOU price is implemented, demand load in the peak, flat and valley load periods would change. For different 
users, the load demand variation amount in different time periods (peak, flat and valley) would be different, which could be represented by their demand elasticity coefficients. Equation (3) shows the demand elasticity coefficients for different users.

$$
e_{i k s t}=\frac{\Delta L_{i k s} / L_{i k s}^{0}}{\Delta P_{i k t} / P_{i k t}^{0}}
$$

wherein $s$ is the index for time, $s=1,2, \ldots, T$; $e_{i k s t}$ is user demand elasticity coefficient of user $i$ in voltage level $k$, it reflects the influence of price variation at time $t$ on load demand variation amount at time $s$. If $s=t, e_{i k s t}$ represents its influence on users' load demand when price changes in the current period; and if $s \neq t, e_{i k s t}$ represents its influence on other period's load demand when price changes in the current period.

Considering the mutual influence of three periods, user $i$ in voltage level $k$ demand elasticity coefficients matrix $E_{i k}$ could be expressed as Equation (4):

$$
E_{i k}=\left[\begin{array}{ccc}
e_{i k \mathrm{pp}} & e_{i k \mathrm{pf}} & e_{i k \mathrm{pv}} \\
e_{i k \mathrm{fp}} & e_{i k \mathrm{ff}} & e_{i k \mathrm{fv}} \\
e_{i k \mathrm{vp}} & e_{i k \mathrm{vf}} & e_{i k \mathrm{vv}}
\end{array}\right]
$$

wherein $\Delta L_{i k p}, \Delta L_{i k f}$ and $\Delta L_{i k v}$ are respectively total demand variation amount of user $i$ in voltage level $k$ in three periods after TOU price. Based on Equations (3) and (4) $\Delta L_{i k p}, \Delta L_{i k f}$ and $\Delta L_{i k v}$ could be calculated by Equation (5):

$$
\left[\begin{array}{c}
\Delta L_{i k \mathrm{p}} \\
\Delta L_{i k \mathrm{f}} \\
\Delta L_{i k \mathrm{v}}
\end{array}\right]=\left[\begin{array}{ccc}
L_{i k p}^{0} & 0 & 0 \\
0 & L_{i k f}^{0} & 0 \\
0 & 0 & L_{i k v}^{0}
\end{array}\right] E_{i k}\left[\begin{array}{l}
\Delta P_{i k \mathrm{p}} / P_{i k p}^{0} \\
\Delta P_{i k \mathrm{f}} / P_{i k f}^{0} \\
\Delta P_{i k \mathrm{v}} / P_{i k v}^{0}
\end{array}\right]
$$

wherein $L_{i k p}^{0}, L_{i k f}^{0}$ and $L_{i k v}^{0}$ are respectively the total demand loads of user $i$ in voltage level $k$ in three periods, and they could be calculated by Equations (6)-(8):

$$
\begin{gathered}
L_{i k p}^{0}=\sum_{t, t \in \text { peak }} L_{i k t}^{0} \\
L_{i k f}^{0}=\sum_{t, t \in f l a t} L_{i k t}^{0} \\
L_{i k v}^{0}=\sum_{t, t \in \text { valley }} L_{i k t}^{0}
\end{gathered}
$$

Assume the demand load change rate in the same period (peak, flat or valley) is fixed. Then peak, flat and valley periods' load demand with TOU price could be calculated according to Equation (2), wherein $\Delta L_{i k t}$ in different periods could be calculated by Equation (9):

$$
\Delta L_{i k t}= \begin{cases}\Delta L_{i k \mathrm{p}} \cdot \frac{L_{i k t}^{0}}{L_{i k p}^{0}} & , t \in \text { peak } \\ \Delta L_{i k f} \cdot \frac{L_{i k t}^{0}}{L_{i k f}^{0}} & , t \in \text { flat } \\ \Delta L_{i k v} \cdot \frac{L_{i k t}^{0}}{L_{i k v}^{0}} & , t \in \text { valley }\end{cases}
$$


The load demand after TOU price $G_{t}$ could be expressed as Equation (10):

$$
G_{t}=\sum_{i=1}^{I} \sum_{k=1}^{K} L_{i k t} /\left(1-l_{k}\right)
$$

From the above analysis, TOU price would influence load demand distribution and units' output power. Therefore, TOU price can be regarded as a function of independent variables $\Delta L_{i k p}, \Delta L_{i k f}$ and $\Delta L_{i k v}$. The variable $G_{t}$ can be calculated by Equation (11):

$$
G_{t}=G_{t}\left(\Delta P_{i k \mathrm{p}}, \Delta P_{i k \mathrm{f}}, \Delta P_{i k \mathrm{v}}\right)
$$

\section{Energy Storage Systems Charging and Discharging Model}

In traditional electricity generation mode power generation, transmission and allocation progresses are happening at almost the same time. This characteristic would influence electric system's planning, construction, scheduling and controlling mechanisms. Energy storage systems are both power sources and loads; in valley load period, ESSs could charge as a load, and in peak periods ESSs could discharge as a power source. Large-scale energy storage system could effectively decrease peak-valley load ratio, improve electricity quantity, improve power supply stability and promote renewable energy grid connection.

While charging or discharging the ESS itself would also consume some energy. Therefore, considering energy conversion efficiency ESSs' charging-discharging behavior at time t should meet Equation (12):

$$
\left(Q_{0}+\sum_{t=1}^{t^{\prime}} Q_{t}^{+}-Q_{t^{\prime}}\right) \cdot p_{e s s}=\sum_{t=1}^{t^{\prime}} Q_{t}^{-}
$$

wherein $t^{\prime}$ is the index for time, $t^{\prime}=1,2, \ldots T ; Q_{0}$ is the initial storage electricity of the ESSs; $Q_{t^{\prime}}$ is the storage electricity of ESSs at time $t^{\prime} ; Q_{t}^{+}$is the charging power of ESSs at time $t ; Q_{t}^{-}$is the discharging power of ESSs at time $t$; Pess is the energy conversion efficiency coefficient of ESS. Equation (12) states that the original storage energy plus charging gains minus the current storage capacity and then multiplies energy efficiency coefficient should be equal to the summation of discharging.

Assume ESSs could not charge and discharge at the same time, its charging-discharging status should meet Equation (13):

$$
Q_{t}^{+} \cdot Q_{t}^{-}=0
$$

wherein $Q_{t}^{+}$is charging power of the ESSs at time $t$; $Q_{t}^{-}$is discharging power of ESSs at time $t$.

ESSs charging and discharging power is constrained by its max power limitations:

$$
\begin{aligned}
& 0 \leq Q_{t}^{+} \leq \overline{Q^{+}} \\
& 0 \leq Q_{t}^{-} \leq \overline{Q^{-}}
\end{aligned}
$$

wherein $\overline{Q^{+}}$is the max charging power limitation of the ESSs; $\overline{Q^{-}}$is the max discharging power limitation of the ESSs.

The electricity storage in ESSs should be not more than the total storage capacity:

$$
Q_{t} \leq \bar{Q} \quad, \forall t \in T
$$

wherein $\bar{Q}$ is the storage capacity of ESSs. 


\section{Wind Power Uncertainty Simulation}

Before studying the wind power consumption problem, wind power output and basic wind scenarios should be obtained. Wind turbine output is closely related with wind velocity at the wind turbine's hub part. Therefore, wind power output could be calculated by Equation (17) [29]:

$$
w=\frac{1}{2} c_{w} \rho A v^{3}
$$

wherein $w$ is the available wind power output; $\rho$ is air density; $A$ is the swept area of wind turbine's blades; $v$ is wind velocity at wind turbine's hub part; $c_{w}$ is a nonlinear function concerning Tip Speed Ratio (TSR) and pitch angle.

In the actual calculation, the nonlinear factors in Equation (17) have little influence on wind power output [30], therefore, this paper chooses a piecewise linear function to simplify the calculation of wind power output [31]. Wind power is limited by incoming wind velocity. If the incoming wind velocity is lower than wind turbine's cut-in wind velocity or higher than cut-out wind velocity, a wind turbine would not generate power. The wind turbine's available output power could be calculated by Equation (18):

$$
w_{m, t}^{*}=\left\{\begin{array}{l}
0 \quad, v_{t} \leq v_{\text {in }} \quad \text { or } \quad v_{t}>v_{\text {out }} \\
w_{m, \text { rated }}\left(v_{t}-v_{\text {in }}\right) /\left(v_{m, \text { rated }}-v_{\text {out }}\right) \quad, v_{\text {in }} \leq v_{t} \leq v_{m, \text { rated }} \\
w_{m, \text { rated }}, v_{m, \text { rated }} \leq v_{t} \leq v_{\text {out }}
\end{array}\right.
$$

wherein $M$ is wind turbine number; $m$ is the index of wind turbine, $m=1,2, \ldots, M ; w_{m, t}^{*}$ is the available output of wind turbine $m$ at time $t$; $v_{t}$ is the real-time wind velocity at time $t ; v_{i n}$ and $v_{\text {out }}$ are respectively wind turbine cut-in and cut-out wind velocities; $v_{m \text {,rated }}$ is the rated wind velocity of wind turbine $m$; $w_{m, \text { rated }}$ is the rated output of wind turbine $m$.

\subsection{Wind Power Output Scenario Simulation}

There are many existing methods to simulate wind power output scenarios [32,33]. The Monte Carlo method is a relatively accurate and widely used sampling method. The method has good adaptability, and its errors are only related to the standard deviation and sample size. However, its accuracy is constrained by both the stochastic sampling reliability and the simulation times. Therefore, The Monte Carlo method would consume large amounts of computation time to achieve a satisfactory accuracy. To overcome this flaw of the Monte Carlo method, the Latin Hypercube Sampling method (LHS) has been put forward [33]. It do not require as large amounts of computation time as the Monte Carlo method. Therefore, this paper chooses LHS to simulate wind power output scenarios, the details are as follows [34]:

Assume $\mathrm{X}$ is a $\mathrm{H}$-dimensional random variable. The individual elements $x_{h}(h=1,2, \ldots, H)$ of $\mathrm{X}$ are independent of each other. And $F_{h}(h=1,2, \ldots, H)$ is the probability distribution function for element $x_{h}$, then:

$$
y_{h}=F_{h}\left(x_{h}\right) \quad, y_{h} \in[0,1]
$$

For a given simple size $N$, divide the domain of $y_{h}$ into $N$ non-overlapping intervals of equivalent length, the length of each interval is $1 / \mathrm{N}$. Then for an interval $(n-1, n)$, choose a point of $y_{h}=F_{h}\left(x_{h}\right),(h \in[n-1, n])$ as its sampling value $x_{h n}$. Assume $p_{h n}$ is a uniformly distributed random variable, and its domain is $[0,1]$. Then for the $n$-th sampling, $y_{h n}$ is the probability value of the $h$-th 
element $x_{h}$ of $X$, and $y_{h}$ should be in interval $\left[\frac{n-1}{N}, \frac{n}{N}\right]$. Therefore the $n$-th sampling result could be calculated by Equation (20):

$$
x_{h n}=F_{h}^{-1}\left[\left(n+p_{h n}-1\right) / N\right]
$$

Once all the elements $x_{i}(i=1,2, \ldots, H)$ are sampled, $X$ could be obtained. Then define a sampling result matrix $P=\left[x_{h n}\right]_{H \times N}\left(P=\left[x_{h 1} \ldots x_{h n} \ldots x_{h N}\right]\right)$.

Assume $h(x)$ is a transformation function of two input variables, for example $x_{1}$ and $x_{2}$. And the estimate of expectation value $\bar{h}$ of $h(x)$ could be calculated as:

$$
\bar{h}=\sum_{j=1}^{N} h\left(x_{j}\right) / N
$$

Sample variance depends on the method used to simulate the sample. The variance of random sample is:

$$
\operatorname{var}(\bar{h})=\operatorname{var}(h(x)) / N
$$

The variance of the sample simulated by Latin Hypercube method is:

$$
\operatorname{var}(\bar{h})=\operatorname{var}(h(x)) / N+(N-1) \operatorname{cov}\left(h\left(x_{1}\right), h\left(x_{2}\right)\right) / N
$$

According to Equations (22) and (23), the LHS method decreases the sample variance if $\operatorname{cov}\left(h\left(x_{1}\right), h\left(x_{2}\right)\right)<0$. Literature [35] has indicated that when the sample size $N$ is big enough (much larger than the number of elements $H$ ), the covariance term is asymptotically non-positive. Therefore, it is easier for LHS to achieve convergence than for simple random sampling.

\subsection{Wind Power Scenario Reduction Strategy}

The LHS method could be used to get a wind power output scenarios set. Some similar scenarios should be deleted to simplify the calculation complexity. The basic concept of scenario reduction is to compare a scenario with other scenarios and remove the closest one. The bigger the scenario number, the bigger the scenario reduction workload.

To overcome this problem, many well-known scenario reduction methods have been put forward [36-40]. Römisch, et al. [37] reviewed available scenario reduction techniques and discussed the related open problems. This paper chooses the Kantorovich distance method [27,39], and sets to minimize the Kantorovich distance between the initial scenario and the removed scenario as the reduction objective.

Assume $P^{\prime}$ is a scenario set for a $T$-length time period, and its scenario number is $H$. Therefore, $P^{\prime}=\left\{s_{h}, h=1,2, \ldots H\right\}$, the element of $P^{\prime}$ is $s_{h}=\left\{s_{h}^{t}, t=1,2, \ldots, T\right\}$ and the probability of $s_{h}$ is $p_{h}$. $P^{\prime}$ could be obtained by LHS method. By scenario reduction we could get a reduced scenario set $Q$, which contains all the remaining scenarios after scenario reduction. $Q=\left\{\tilde{s}_{r}, r=1,2, \ldots \tilde{H}\right\}$, the element of $Q$ is $\tilde{s}_{r}=\{, t=1,2, \ldots, T\}$ and the probability of $\tilde{s}_{r}$ is $q_{r}$. The Kantorovich distance could be calculated by Equations (24) and (25):

$$
D_{K}\left(P^{\prime}, Q\right)=\inf \left\{\sum_{h=1}^{H} \sum_{r=1}^{\tilde{H}} \eta_{h r} c_{T}\left(s_{h}, \tilde{s}_{r}\right): \eta_{h r} \geq 0, \sum_{h=1}^{H} \eta_{h r}=q_{r}, \sum_{r=1}^{\tilde{H}} \eta_{h r}=p_{h}, \forall h, \forall r\right\}
$$




$$
c_{T}\left(s_{h}, \tilde{s}_{r}\right)=\sum_{t=1}^{T}\left|s_{h}-\tilde{s}_{r}\right|
$$

Define a removed scenario set $R$, which contains all removed scenarios. Then the Kantorovich distance could be calculated by Equation (26):

$$
D_{K}\left(P^{\prime}, Q\right)=\sum_{h \in R} p_{h} \min _{r \notin R} c_{T}\left(s_{h}, \tilde{s}_{r}\right)
$$

Approximately regard $q_{r}$ as the summation of the scenario's occurrence probability in the initial scenario and the closest removed scenario's occurrence probability. The details are:

$$
\begin{gathered}
q_{r}=p_{r}+\sum_{h \in R(r)} p_{h} \\
R(r)=\{h \in R: r=r(h)\} \\
r(h) \in \arg \min _{h \in R(r)} c_{T}\left(s_{h}, \tilde{s}_{r}\right), \forall h \in R
\end{gathered}
$$

Then build a wind power scenario reduction optimization method based on Equations (24)-(29). Assume $N_{R}$ is the number of scenarios that have been removed. The optimized scenario reduction method can be expressed by Equation (30):

$$
\min \left\{\sum_{h \in R} p_{h} \min _{h \notin R} c_{T}\left(s_{h}, \tilde{s}_{r}\right): R \subset\{1,2, \ldots, H\}, N_{R}=H-\tilde{H}\right\}
$$

According to Equation (30), the scenario reduction mechanism would influence the reduction result directly. To set appropriate scenario removing number, this paper sets the maximum reduction strategy as Equation (31):

$$
\sum_{h \in R} p_{h} \min _{r \notin R} c_{T}\left(s_{h}, \tilde{s}_{r}\right) \leq \beta
$$

Equation (31) is to ensure the similar degree of the scenario set after scenario and the initial scenario set is in the required range. The scenario reduction model consists of Equations (24)-(31). To solve this model, this paper uses the multi-stage heuristic algorithm, referring to [33].

\section{Power Generation Scheduling Optimization Model with Wind Power}

Power generation scheduling schemes are determined by user demand. The scheduling center makes power generation plans for generation units based on the demand load curve. Since wind power has low variable cost, improving the wind power utilization level could decrease energy consumption during power generation. However, since wind power is intermittent and unstable, backup services are needed for its grid connection. This makes system scheduling problems more complicated. Therefore, how to allocate units' output and get more economic benefits is the key problem for power generation scheduling. To decrease energy consumption, this paper sets to minimize coal consumption as the optimization goal and builds energy-saving power generation scheduling mode. The optimization objective is expressed as Equation (32):

$$
\operatorname{Min} z_{1}=\sum_{t=1}^{T} \sum_{j=1}^{J}\left[u_{j t} f_{j}\left(g_{j t}\right)+u_{j t}\left(1-u_{j, t-1}\right) S_{j t}\right]
$$


wherein $J$ is thermal unit number; $j$ is the index for thermal unit, $j=1,2, \ldots, J$; $u_{j t}$ is a $0-1$ variable, $u_{j t}=1$ represents unit $j$ is on operation at time $t$ and $u_{j t}=0$ represents unit $j$ is shutdown at time $t ; S_{j t}$ is startup coal consumption of unit $j ; g_{j t}$ is the output of unit $j$ at time $t ; f_{j}\left(g_{j t}\right)$ is a quadratic function for power generation coal consumption, its equation is:

$$
f_{j}\left(g_{j t}\right)=a_{j} g_{j t}^{2}+b_{j} g_{j t}+c_{j}
$$

wherein $a_{j}, b_{j}$ and $c_{j}$ are coal consumption parameters of thermal unit $j$. The scheduling schemes should meet the following constraints:

(1) Electricity demand and supply balance constraint:

$$
\sum_{j=1}^{J} u_{j t} g_{j t}\left(1-p_{j}\right)+\sum_{m=1}^{M} w_{m, t}\left(1-p_{m}\right)=G_{t}
$$

wherein $p_{j}$ is the auxiliary power consumption rate of unit $j ; p_{m}$ is the auxiliary power consumption rate of wind turbine $m$.

(2) System maximum backup service constraints:

$$
\begin{gathered}
\sum_{j=1}^{J} u_{j t}\left(g_{j, t}^{\max }-g_{j t}\right)\left(1-p_{j}\right) \geq R_{t}+R_{t}^{0, \max } \\
g_{j, t+1}^{\max }=\min \left(u_{j t} g_{j, t}^{\max }, g_{j t}+\Delta g_{j}^{+}\right) \cdot u_{j, t}
\end{gathered}
$$

wherein $g_{j, t}^{\max }$ is max limitation of thermal unit $j$ at time $t ; R_{t}$ is the backup service demand without TOU price and ESSs at time $t ; R_{t}^{0, \max }$ is the max limitation of system spinning reserve without TOU price and ESSs at time $t ; \Delta g_{j}^{+}$is the max climbing limitation of unit $j$ output power.

(3) System minimum backup service constraints:

$$
\begin{gathered}
\sum_{j=1}^{J} u_{j t}\left(g_{j t}-g_{j, t}^{\min }\right)\left(1-p_{j}\right) \geq R_{t}^{0, \min } \\
g_{j, t+1}^{\min }=\max \left(u_{j t} g_{j, t}^{\min }, g_{j t}-\Delta g_{j}^{-}\right) \cdot u_{j, t}
\end{gathered}
$$

wherein $g_{j, t}^{\min }$ is the min limitation of thermal unit $j$ at time $t ; R_{t}^{0, \min }$ is the min limitation of system spinning reserve without TOU price and ESSs at time $t ; \Delta g_{j}^{-}$is the max climbing limitation of unit $j$ output power.

(4) Wind power real-time output constraint:

$$
\sum_{m=1}^{M} w_{m, t} \leq \lambda_{t} w_{c}
$$

wherein $\lambda_{t}$ is the equivalent utilization coefficient of wind power at time $t$.

(5) Thermal units output constraint:

$$
u_{j t} g_{j, t}^{\min } \leq g_{j t} \leq u_{j t} g_{j, t}^{\max }
$$

(6) Thermal units power climbing constraint:

$$
\Delta g_{j}^{-} \leq g_{j t}-g_{j, t-1} \leq \Delta g_{j}^{+}
$$


(7) Thermal units' start time constraints:

$$
\left(T_{j, t-1}^{\mathrm{on}}-M_{j}^{\mathrm{on}}\right)\left(u_{j, t-1}-u_{j t}\right) \geq 0
$$

wherein $T_{j, t-1}^{\text {on }}$ is the continuous operation time of unit $j$ at time $t-1 ; M_{j}^{\text {on }}$ is the min operation time limitation of unit $j$.

(8) Thermal units' downtime constraints:

$$
\left(T_{j, t-1}^{\mathrm{off}}-M_{j}^{\text {off }}\right)\left(u_{j t}-u_{j, t-1}\right) \geq 0
$$

wherein $T_{j, t-1}^{\text {off }}$ is the continuous shutdown time of unit $j$ at time $t-1 ; M_{j}^{\text {off }}$ is the min limitation shutdown time of unit $j$.

The scheduling model achieves energy-saving by controlling the startup-shutdown and units output. Therefore, the decision variables in the model are units' startup-shutdown statue variable $u_{j t}$, units' output variable $g_{j t}$ and wind power's real-time output variable $w_{m, t}$.

\section{Power Generation Scheduling Optimization Model Considering ESSs and DRPs}

DRPs and ESSs could change demand load distribution. The distribution would influence the power generation scheduling scheme. Therefore, a power generation scheduling scheme can be optimized with the influence of DPRs and ESSs. According to the operation mechanism, DRPs and ESSs could help load shifting, decrease load volatility and decrease units' scheduling pressure. Then, units with high effectiveness and low coal consumption rate would output more, units with low effectives and high coal consumption level would output less or not generate. In this way, system average coal consumption could be decreased.

According to the above analysis, this paper sets thermal units' real-time output, operation statue, wind power real-time output, ESSs real-time charging and discharging power and TOU price change as the decision variables and builds a power generation scheduling optimization model with ESSs and DRPs. The optimization objective is still minimizing total coal consumption:

$$
\text { Min } z_{2}=\sum_{t=1}^{T} \sum_{j=1}^{J}\left[u_{j t} f_{j}\left(g_{j t}\right)+u_{j t}\left(1-u_{j, t-1}\right) S_{j t}\right]
$$

The scheduling schemes should meet the following constraints Equations (1)-(16),(18),(33),(38)-(43).

Besides, they should meet constrains of ESSs and backup services:

(1) ESSs charging and discharging constraint:

$$
\sum_{j=1}^{J} u_{j t} g_{j t}\left(1-p_{j}\right)+\sum_{m=1}^{M} w_{m, t}\left(1-p_{m}\right)+Q_{t}^{-}=G_{t}+Q_{t}^{+}
$$

(2) The max and min backup service limitation constraints of wind power considering ESSs and DRPs:

$$
\sum_{j=1}^{J} u_{j t}\left(g_{j, t}^{\max }-g_{j t}\right)\left(1-p_{j}\right) \geq R_{t}+R_{t}^{\max }
$$

wherein $R_{t}^{\max }$ is the max limitation of system spinning reserve with TOU price and ESSs at time $t$ : 


$$
\sum_{j=1}^{J} u_{j t}\left(g_{j t}-g_{j, t}^{\min }\right)\left(1-p_{j}\right) \geq R_{t}^{\min }
$$

wherein $R_{t}^{\min }$ is the min limitation of system spinning reserve with TOU price and ESSs at time $t$.

\section{Linear Processing}

The decision variables of the optimization model contains continues variables and $0-1$ variables, which is a mixed integer optimization problem. Thermal units' real-time output is a decision variable, the relationship between the real-time output and coal consumption is expressed as a quadratic function $f_{j}(g)$. The optimization objective function contains a multiplication of a $0-1$ variable and a quadratic term. Therefore, the power generation scheduling optimization problem is a mixed integer nonlinear programming problem [41]. Algorithms for mixed integer nonlinear programming problems are general complicated with slowly convergence. Therefore, referring to [42] this paper divides thermal units' power generation coal consumption function into segments. In each segment the relationship could be expressed in a linear function. In this way the quadratic optimization problem is transferred into a linear optimization (shown in Figure 1).

Figure 1. Liner processing of quadratic function.

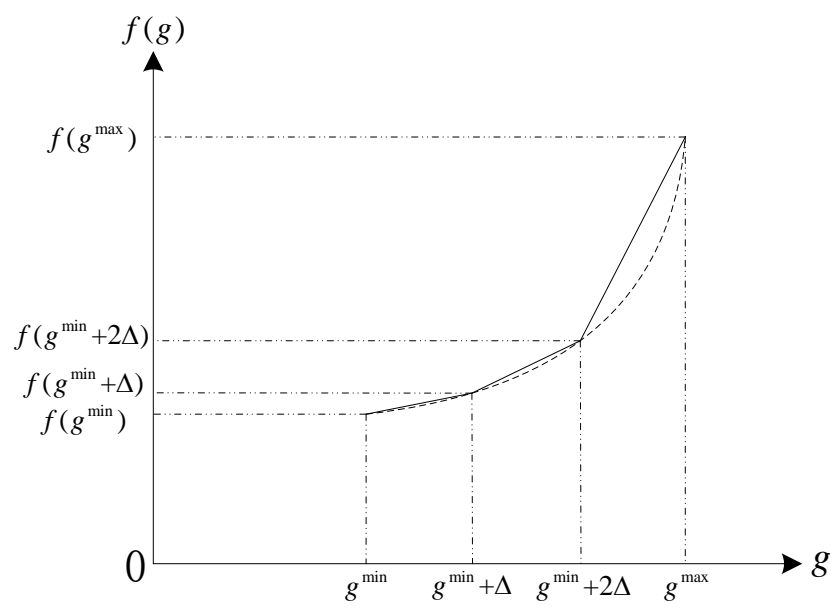

Assume the quadratic function has been divided into $N$ segments. Then the function could be expressed as a piecewise linear function [42] $f_{j}^{\prime}(g)$. When $g \in\left[g^{\min }+n \Delta, g^{\min }+(n+1) \Delta\right]$ :

$$
f_{j}^{\prime}(g)=f\left(g^{\min }+n \Delta\right)+\left(g-g^{\min }-n \Delta\right) *\left[b+(2 n+1) c \Delta+2 c g^{\min }\right]
$$

In Equation (48) $n=0,1, \ldots, N-1$ and $\Delta$ is the length of the segments $\Delta=\left(g^{\max }-g^{\min }\right) / N$.

For optimization of objective Equations (32) and (44), the multiplication of two binary variables should be dealt with. This paper divides the calculation of startup-shutdown coal consumption $\sum_{t=1}^{T} \sum_{j=1}^{J} u_{j t}\left(1-u_{j, t-1}\right) S_{j t}$ into two parts, i.e., unit startup part and shutdown part. And the startup-shutdown coal consumption of unit $j$ at time $t$ could be calculated by Equations (49) and (50): 


$$
\begin{aligned}
S_{j t}^{\text {startup }} & =\left\{\begin{array}{l}
\omega_{\text {startup }}\left(u_{j, t}-u_{j, t-1}\right) \\
0 \quad, u_{j, t}<u_{j, t-1}
\end{array}, u_{j, t} \geq u_{j, t-1}\right. \\
S_{j t}^{\text {shutdown }} & =\left\{\begin{array}{l}
\omega_{\text {shutdown }}\left(u_{j, t-1}-u_{j, t}\right) \\
0, u_{j, t}>u_{j, t-1}
\end{array}, u_{j, t} \leq u_{j, t-1}\right.
\end{aligned}
$$

wherein $S_{j t}^{\text {startup }}$ and $S_{j t}^{\text {shutdown }}$ are respectively startup and shutdown coal consumption of unit $j$ at time $t$; $\omega_{\text {startup }}$ and $\omega_{\text {shutdown }}$ are coal consumption coefficient of thermal unit startup and shutdown, in this simulation $\omega_{\text {startup }}=\omega_{\text {shutdown }}$. And total coal consumption amount could be calculated by Equation (51):

$$
\sum_{t=1}^{T} \sum_{j=1}^{J} u_{j t}\left(1-u_{j, t-1}\right) S_{j t}=\sum_{t=1}^{T} \sum_{j=1}^{J} S_{j t}^{\text {startup }}+\sum_{t=1}^{T} \sum_{j=1}^{J} S_{j t}^{\text {shutdown }}
$$

The simulation has been implemented in the GAMS optimization software using CPLEX 11.0 linear solver. The CPU time required for solving the problem for different case studies with an idea pad 450 series laptop computer powered by core T4300 processor and 2 GB of RAM was less than $10 \mathrm{~s}$.

\section{Case Study}

\subsection{Simulation Scenarios}

To study ESSs' and DRPs' influence on system wind power consumption capacity, this paper sets four simulation scenarios:

Case 1: Basic scenario. In this case ESSs and DRPs are not considered, it is a scheduling optimization problem with wind power.

Case 2: ESSs scenario. In this case ESSs are taken into consideration but DRPs is not. Four energy storage systems are added into the scheduling system. The storage capacity is $400 \mathrm{MW}$ and the charging-discharging power limitation is $80 \mathrm{MW}$.

Case 3: DRPs scenario. In this case DRPs is taken into consideration but ESSs are not. The electricity price in peak load period and valley load period are respectively increased and decreased by $25 \%$.

Case 4: ESSs and DRPs scenario. In this case both ESSs and DRPs are taken into consideration. Four energy storage systems are added into the scheduling system and the electricity price in peak load period and valley load period are increased and decreased by $25 \%$ respectively.

\subsection{Basic Data}

To simulate the model proposed by this paper, 10 thermal units, one wind power farm and four energy storage systems are chose as the simulation system. According to demand load distribution characteristics and voltage level, users could be classified into A and B types. Both A and B have I, II and III three different voltage level users. Load demand distributions of users are shown in Figure 2. The line-loss of voltage level I, II and III are respectively 5.5\%, 5.0\% and 4.5\%. Electricity prices before implementing TOU of user type AI, AII and AIII are respectively 464, 444 and $424 \mathrm{Yuan} / \mathrm{MW} \cdot \mathrm{h}$, and of user type BI, BII and BIII are respectively 623, 593 and $563 \mathrm{Yuan} / \mathrm{MW} \cdot \mathrm{h}$. 
According to the TOU price mechanism, $24 \mathrm{~h}$ are divided into three periods, namely peak load, flat load and valley load periods. Valley load period contains time zone 0:00-5:00 and 21:00-24:00, flat load period contains 5:00-8:00 and 14:00-19:00 and peak load period contains 8:00-14:00 and 19:00-21:00. Electricity price in the peak load period is increased by $25 \%$ and in the valley period is decreased by $25 \%$. Demand elasticity coefficients matrixes of type A and B are:

$$
\begin{aligned}
& E_{A}=\left[\begin{array}{ccc}
-0.25 & 0.31 & 0.28 \\
0.23 & -0.25 & 0.24 \\
0.18 & 0.11 & -0.25
\end{array}\right] \\
& E_{B}=\left[\begin{array}{ccc}
-0.23 & 0.10 & 0.14 \\
0.20 & -0.22 & 0.23 \\
0.35 & 0.25 & -0.25
\end{array}\right]
\end{aligned}
$$

Figure 2. Load distribution of various users in different voltage ranges (MW).
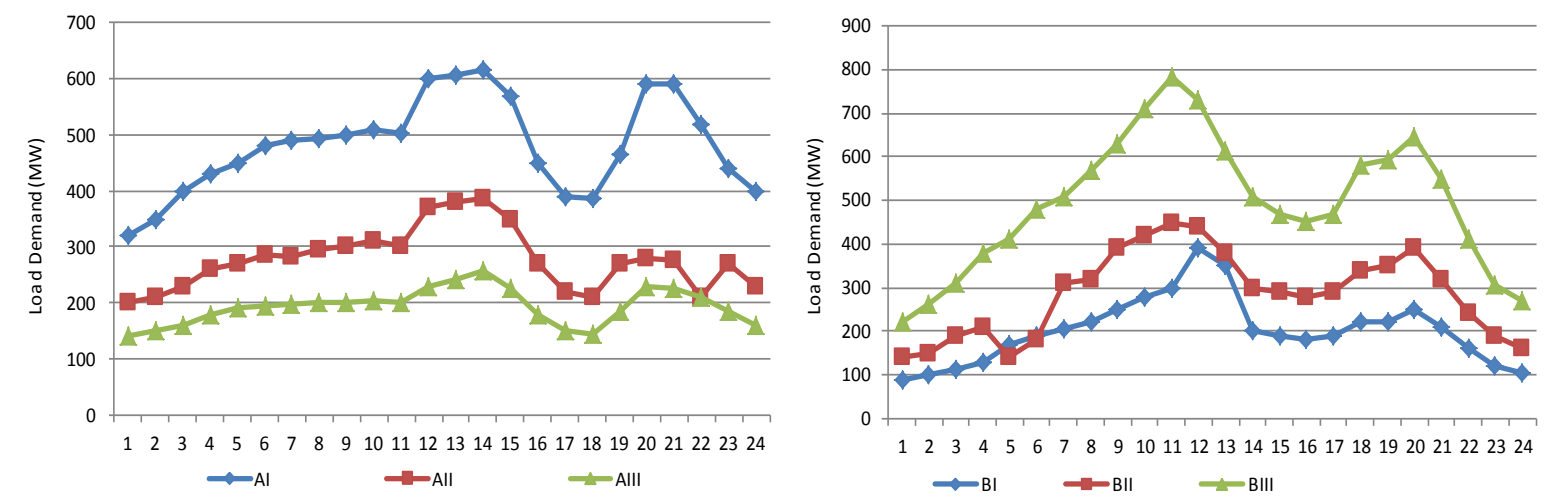

The max limitation of storage energy of an energy storage system is $100 \mathrm{MW} \cdot \mathrm{h}$, the max limitation of its charging and discharging power is $20 \mathrm{MW}$. The initial storage energy of an energy storage system is $0 \mathrm{MW} \cdot \mathrm{h}$. The coefficients of thermal units are listed in Table 1. From unit 1\# to unit 10\#, the installed capacity, coal consumption coefficient, pollutant emission coefficient and startup-shutdown time are decreasing while energy efficiency is decreasing.

Table 1. Coefficients of thermal power units.

\begin{tabular}{cccccccccccc}
\hline \multirow{2}{*}{ Unit } & $\begin{array}{c}g_{j}^{\min } \\
(\mathbf{M W})\end{array}$ & $\begin{array}{c}g_{j}^{\max } \\
(\mathbf{M W})\end{array}$ & $\begin{array}{c}\Delta g_{j}^{+} \\
(\mathbf{M W} / \mathbf{h})\end{array}$ & $\begin{array}{c}\Delta g_{j}^{-} \\
(\mathbf{M W / h})\end{array}$ & $\boldsymbol{a}_{j}$ & $\boldsymbol{b}_{j}$ & $\boldsymbol{c}_{j}$ & $\begin{array}{c}M T_{j}^{\text {on }} \\
(\mathbf{h})\end{array}$ & $\begin{array}{c}M T_{j}^{\text {off }} \\
(\mathbf{h})\end{array}$ & $\begin{array}{c}\boldsymbol{S}_{\boldsymbol{i t}} \\
(\mathbf{t})\end{array}$ & $\boldsymbol{\theta}_{\boldsymbol{i}}$ \\
\hline $1 \#$ & 250 & 600 & 280 & -280 & $6.44 \times 10^{-6}$ & 0.274 & 11.71 & 8 & 8 & 25.6 & $4.9 \%$ \\
$2 \#$ & 200 & 500 & 240 & -240 & $8.08 \times 10^{-6}$ & 0.282 & 9.79 & 8 & 8 & 23.1 & $5.3 \%$ \\
$3 \#$ & 200 & 450 & 210 & -210 & $1.12 \times 10^{-5}$ & 0.293 & 8.88 & 7 & 7 & 22.3 & $5.2 \%$ \\
$4 \#$ & 180 & 400 & 180 & -180 & $1.84 \times 10^{-5}$ & 0.297 & 8.48 & 7 & 7 & 19.6 & $5.7 \%$ \\
$5 \#$ & 150 & 350 & 150 & -150 & $2.40 \times 10^{-5}$ & 0.304 & 7.27 & 6 & 6 & 16.2 & $6.1 \%$ \\
$6 \#$ & 150 & 300 & 150 & -150 & $3.66 \times 10^{-5}$ & 0.308 & 6.17 & 5 & 5 & 15.4 & $7.1 \%$ \\
$7 \#$ & 120 & 300 & 120 & -120 & $3.74 \times 10^{-5}$ & 0.317 & 5.26 & 4 & 4 & 12.3 & $6.8 \%$ \\
$8 \#$ & 100 & 250 & 100 & -100 & $4.59 \times 10^{-5}$ & 0.328 & 4.65 & 4 & 4 & 8.1 & $7.3 \%$ \\
$9 \#$ & 70 & 150 & 70 & -70 & $4.15 \times 10^{-5}$ & 0.332 & 3.54 & 3 & 3 & 4.3 & $8.3 \%$ \\
$10 \#$ & 30 & 100 & 50 & -50 & $9.01 \times 10^{-5}$ & 0.337 & 1.43 & 2 & 2 & 2.1 & $7.7 \%$ \\
\hline
\end{tabular}


In this case the total installed wind power capacity is $1000 \mathrm{MW}$. Based on the wind power output scenario simulation method in Section 4.1., we used Matlab to get 100 kinds of basic wind power output scenarios. Then we remove scenarios according to the introduced scenario reduction strategy, and finally keep 20 kinds of basic wind power output scenarios as the basic data of the optimization model. To simplify the calculation, this paper uses the average value of wind power output in $24 \mathrm{~h}$ in the 20 cases as available wind power output, as shown in Table 2.

Table 2. $24 \mathrm{~h}$ output power of wind farm.

\begin{tabular}{cc|cc|cc}
\hline Time & $\begin{array}{c}\text { Available wind power } \\
(\mathbf{M W} \cdot \mathbf{h})\end{array}$ & Time & $\begin{array}{c}\text { Available wind power } \\
(\mathbf{M W} \cdot \mathbf{h})\end{array}$ & Time & $\begin{array}{c}\text { Available wind power } \\
(\mathbf{M W} \cdot \mathbf{h})\end{array}$ \\
\hline 1 & 581.5 & 9 & 716.9 & 17 & 480.0 \\
2 & 726.2 & 10 & 495.4 & 18 & 372.3 \\
3 & 646.2 & 11 & 572.3 & 19 & 264.6 \\
4 & 680.0 & 12 & 633.8 & 20 & 406.2 \\
5 & 667.7 & 13 & 732.3 & 21 & 523.1 \\
6 & 683.1 & 14 & 923.1 & 22 & 310.8 \\
7 & 843.1 & 15 & 812.3 & 23 & 415.4 \\
8 & 747.7 & 16 & 756.9 & 24 & 566.2 \\
\hline
\end{tabular}

\subsection{Simulation Results}

\subsubsection{Case 1: Self-Scheduling Results of System in the Basic Scenario}

Case 1 is a reference for the other three cases. ESSs and DRPs are not considered in this case. With the objective of minimizing power generation coal consumption, thermal units and wind power output scheduling results are optimized. Figure 3 shows their output structure in Case 1. According to Figure 3, in flat and valley load periods, load is mainly allocated to unit 1\#, 2\# and 3\#. In those periods, unit $1 \#$ is always in full generation statue and unit $2 \#$ almost in full generation statue. In peak load period unit 4\#, 5\# and 7\# are called.

Figure 3. Thermal units and wind power output in Case 1.

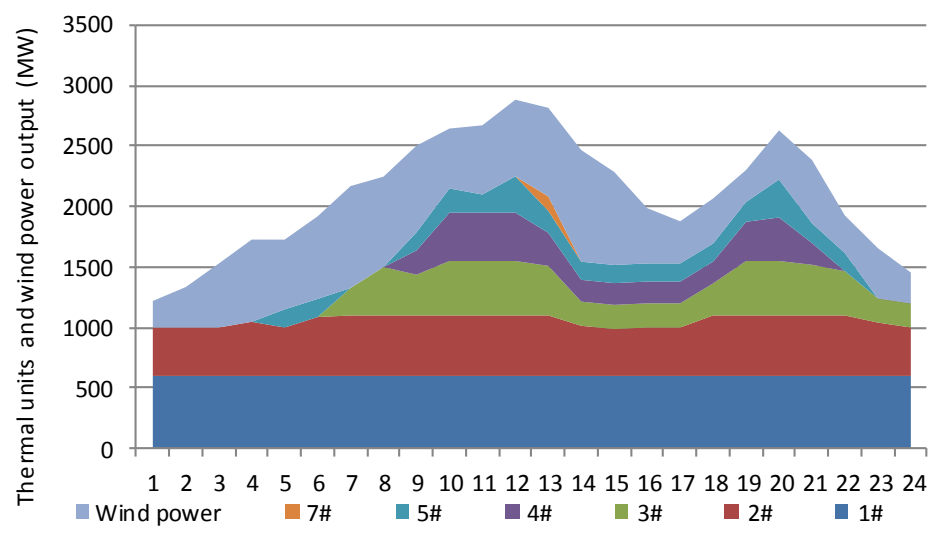

In the flat load period and valley load period, load demand and load variation are relatively small, so units with high energy efficiency and small pollutant emission has a priority to be called, so units $1 \#$ and $2 \#$ are called all the time and unit $3 \#$ is called to adapt to the load variation. In the peak load period, 
load demand increases and changes quickly, units 1\# and 2\# are already in full power generation statue. Although unit $3 \#$ is better than other units, unit 3\# could not meet the load variation requirement since it need more time to startup-shutdown than small capacity units. Therefore, units with smaller capacity and shorter startup-shutdown time were called to generate. In Case 1, the total coal consumption is 12,006 t.

\subsubsection{Case 2: Self-Scheduling Results of System in the ESSs Scenario}

In Case 2, this paper considers ESS' influence on load demand and system wind power consumption capacity. Compared with Case 1, the electricity balance constraint is changed and charging-discharging constraint of ESSs is added in this case. Figure 4 shows thermal units and wind power output structure in Case 2. According to Figure 4, in the flat load period and valley load period, the output structure is similar to that in Case 1. Load is mainly allocated to units $1 \#$ and 2\# and unit 3\# is called for adaptation. In the peak load period units $4 \#, 5 \#$ and $8 \#$ are called.

Figure 4. Thermal units and wind power output in Case 2.

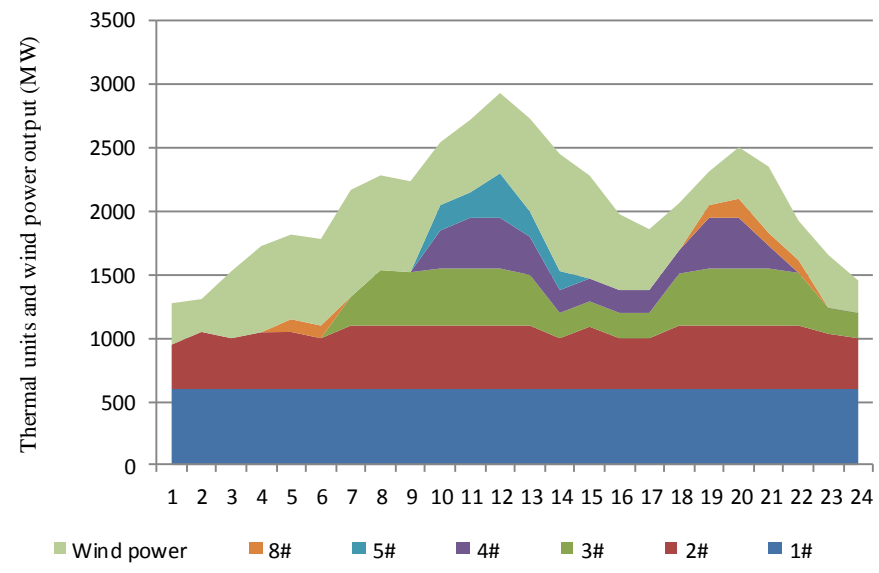

The energy storage system can influence the demand load curve by its charging and discharging behavior, making the load curve smoother and load demand changes not as quickly as that in Case 1 . Compared with Case 1, small installed capacity units' output decreased, units 2\# and 3\# output increased (such as 4-7 and 15-17 period). In Case 2 the total coal consumption is 11,702 t.

\subsubsection{Case 3: Self-Scheduling Results of System in the DRPs Scenario}

In Case 3, TOU price's influence on load demand is considered and the electricity price in the peak load period and valley load period are respectively increased and decreased by $25 \%$. According to Equations (1)-(11) load demand with demand response could be calculated. Demand load curves with and without demand response are drawn in Figure 5. When considering demand response load demands in peak load period were decreased and load demand in valley load period was increased.

The optimized thermal units and wind power output structure of this case are shown in Figure 6. In Case 3, large capacity units' output steadily, and other units were mainly called in peak load period. Because of the influence of demand response, the demand load curve has become much smoother, which makes units $1 \#$ and $2 \#$ generate steadier and the units called for peak shaving could be used for wind power's backup service. In Case 3 total coal consumption is 11,258 t. 
Figure 5. Load demand curve before and after considering demand response.

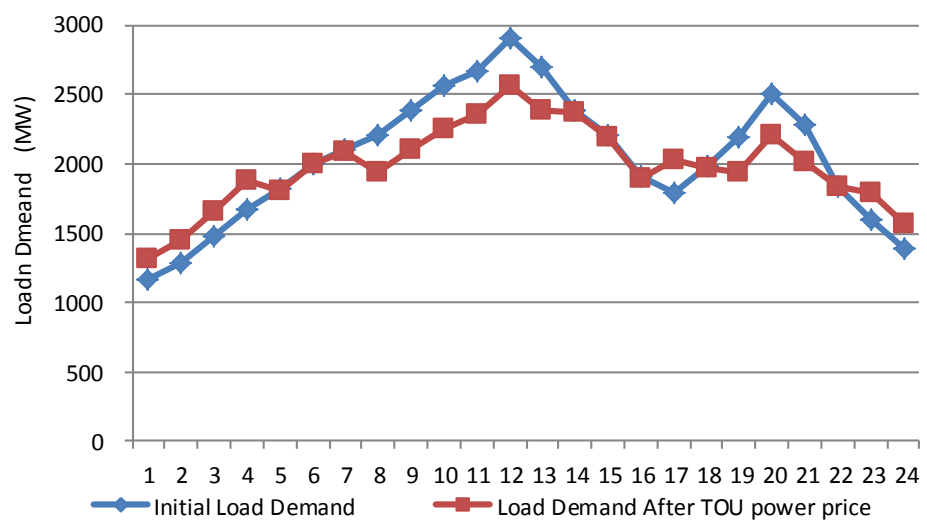

Figure 6. Thermal units and wind power output in Case 3.

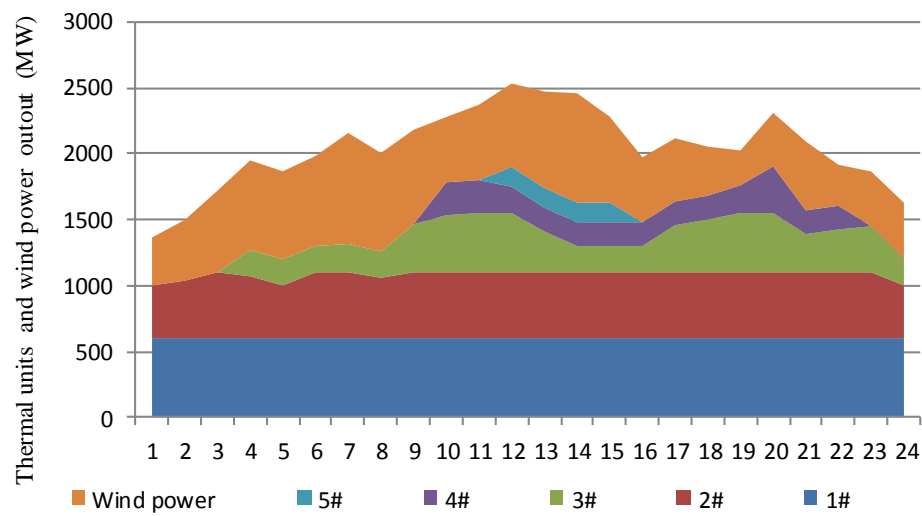

8.3.4. Case 4: Self-Scheduling Results of the System in the ESSs and DRPs Scenario

In Case 4 the influence of ESSs and DRPs are considered. The optimized thermal units and wind power output structure are shown in Figure 7. Compared with the former three cases, units $1 \#$ and $2 \#$ generate steadily, unit $3 \#$ generates in the flat load period, and unit $5 \#$ is called in the flat and peak load period.

Figure 7. Thermal units and wind power output in Case 4.

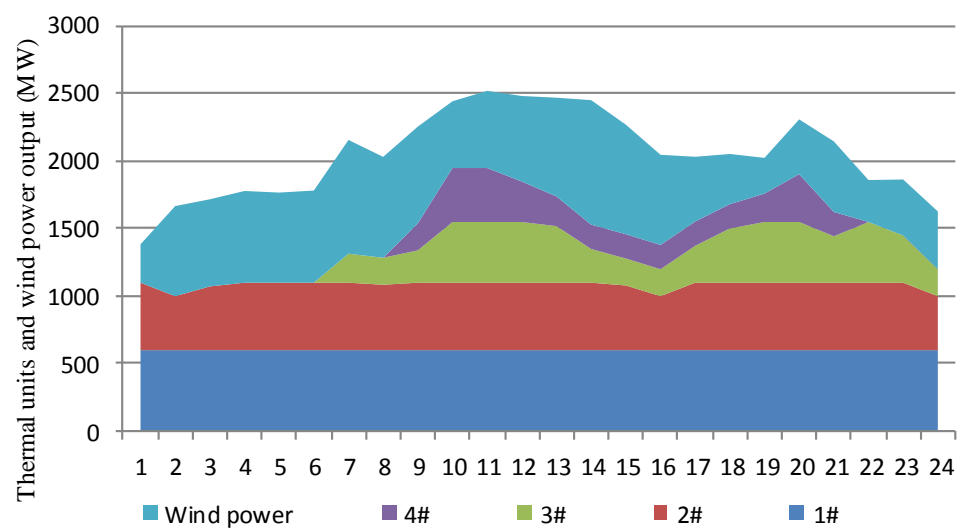

With the influence of ESSs and DRPs, system's demand load curve has become smoother. Load was mainly allocated to high energy efficiency and small pollutant emission units. In the valley load period, the demand load was increased and small capacity thermal units could act as backup service, so wind 
power output increased significantly. In Case 4 total coal consumption is $11,022 \mathrm{t}$, which is the lowest of the four cases.

\subsection{Result Analysis}

To compare wind power consumption, and the system's economic and environmental benefits in different cases this paper comparatively analyzes demand load, wind power output, energy storage system charging-discharging behavior, thermal units' output and system's economic and environmental benefits in four cases.

\subsubsection{Demand Load}

The system's load structure in the four cases is listed in Table 3. Compared with Case 1, in Case 2, the load proportions of the valley load and flat load periods increased while the load proportion of the peak load period decreased. The maximum demand load decreased while the minimum demand load remained the same, and the peak-valley ratio decreased from 2.26 to 2.20. In Case 3, load proportions changed like those in Case 2 but more dramatically so. The maximum demand load decreased and the minimum demand load increased, and the peak-valley ratio decreased from 2.26 to 1.77. In Case 4 the variation amount is the maximum. The peak load proportion decreased from $41.06 \%$ to $37.21 \%$ while the valley load proportion increased from $25.93 \%$ to $28.05 \%$. The peak-valley ratio decreased to 1.63 . Those results show that both ESSs and DRPs could help load shifting. The load shifting effect reaches the maximum when both ESSs and DRPs are introduced. Table 3 lists the load demand structures in the four cases.

Table 3. Load demand structure in four cases.

\begin{tabular}{ccccccc}
\hline \multirow{2}{*}{ Cases } & \multicolumn{2}{c}{ Load structure $(\%)$} & Max load & Min load & \multirow{2}{*}{ Peak-Valley ratio } \\
\cline { 2 - 4 } & Valley & Flat & Peak & (MW) & (MW) & \\
\hline Case 1 & 25.93 & 33.01 & 41.06 & 2905 & 1284 & 2.26 \\
Case 2 & 26.09 & 33.16 & 40.74 & 2830 & 1284 & 2.20 \\
Case 3 & 28.38 & 34.35 & 37.27 & 2561 & 1445 & 1.77 \\
Case 4 & 28.50 & 34.29 & 37.21 & 2483 & 1525 & 1.63 \\
\hline
\end{tabular}

\subsubsection{Wind Power Output}

Compared with Case 1, wind power output increased from $12,810 \mathrm{MW} \cdot \mathrm{h}$ to $14,173 \mathrm{MW} \cdot \mathrm{h}$ and the wind power consumption ratio increased from $88.0 \%$ to $97.4 \%$ in Case 4 . Wind power output in Case 1 is the lowest. According to Table 4 in Case 1, abandoned wind power exists in time period 1-3, 5, 15, 16-17, 24 and the total abandoned power is $174 \mathrm{MW} \cdot \mathrm{h}$. Abandoned wind power in four cases are 1747, 1234, 1164 and $383 \mathrm{MW} \cdot \mathrm{h}$, respectively. Wind power output in Case 4 achieves its maximum value. Wind power output mainly increased in flat and valley load periods (time period 0-4 and 15-17). Table 4 shows wind power consumption situations in the four cases, and wind power output in the four cases is drawn in Figure 8. 
Table 4. Wind power consumption situations in four cases.

\begin{tabular}{lcccc}
\hline Cases & $\begin{array}{c}\text { Wind power output } \\
\text { (MW·h) }\end{array}$ & $\begin{array}{c}\text { Total abandoned } \\
\text { wind }(\mathbf{M W} \cdot \mathbf{h})\end{array}$ & $\begin{array}{c}\text { Wind power output proportion } \\
\text { of the total output (\%) }\end{array}$ & $\begin{array}{c}\text { Wind power } \\
\text { consumption ratio (\%) }\end{array}$ \\
\hline Case 1 & $12,810.1$ & 1747 & 26.1 & 88.0 \\
Case 2 & $13,322.6$ & 1234 & 27.2 & 91.5 \\
Case 3 & $13,392.4$ & 1164 & 28.1 & 92.0 \\
Case 4 & $14,173.4$ & 383 & 29.7 & 97.4 \\
\hline
\end{tabular}

Figure 8. Wind power output in the four cases.

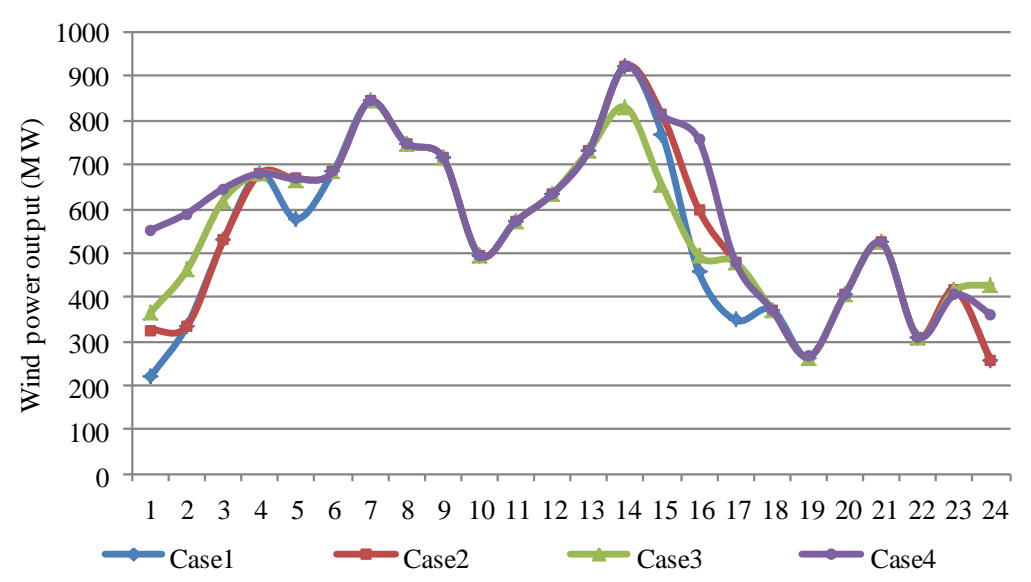

According to the above results, energy storage system and demand response could change demand load distribution to some extent and decreased the peak-valley ratio. In this way, DRPs and ESSs could relieve the scheduling pressure caused by wind power output anti-load distributed characteristics, improve power system wind power consumption capacity and decrease abandoned wind power.

In Case 1, wind power could output effectively only in the peak load period. In the valley load period load is mainly allocated to highly efficient units (units $1 \#$ and 2\#) and abandoned wind power exists. With the influence of ESSs and DRPs the demand load curve becomes smoother and demand load in the valley load period increased. Small capacity units used for peak shaving would be called less. Therefore, small capacity units could provide backup service for wind power in valley load periods. Increased load demand in valley load periods gives wind power more space to output, so abandoned wind power decreased.

\subsubsection{ESSs Charging and Discharging Behavior}

Energy storage system's charging and discharging behaviors in Case 2 and Case 4 are listed in Table 5. Energy storage systems mainly charge in the valley load and flat load periods, which would increase load demand, and discharge in the peak load period, which could supply electricity for power systems. Compared with Case 1, energy storage systems would be more involved in load shifting, and charging-discharging electricity increased in Case 4. 
Table 5. Charging and discharging optimization results of energy storage system $(\mathrm{MW} \cdot \mathrm{h})$.

\begin{tabular}{|c|c|c|c|c|c|c|}
\hline \multirow{2}{*}{ Scenarios } & \multicolumn{2}{|c|}{ Valley period } & \multicolumn{2}{|c|}{ Flat period } & \multicolumn{2}{|c|}{ Peak period } \\
\hline & Charging & Discharging & Charging & Discharging & Charging & Discharging \\
\hline Case 2 & 80.5 & 0.5 & 75.8 & - & - & 155.8 \\
\hline Case 4 & 131.3 & 51.3 & 156.3 & 156.3 & 62.6 & 142.6 \\
\hline
\end{tabular}

\subsubsection{Thermal Power Output}

Thermal units' total output keeps decreasing from Case 1 to Case 4. Unit 1\# remains in full generation mode in the four cases, and unit 2\#'s output increased from 10,975 MW in Case 1 and Case 2 to 11,023 MW in Case 3 and 11,565 MW in Case 4. The output of unit 3\# also increased from Case 1 to Case 4. Conversely, the unit 4\#, 5\# and 7\# output decreased. Unit 8\# is only called to generate in Case 2.

For thermal units, the smoother demand load curve reduces the load shifting requirement, which means less startup-shutdown times. Units with high efficiency and low pollutant emission are more called to generate. In this way, power generation coal consumption and startup-shutdown coal consumption are decreased. However, with the influence of ESSs and DRPs, thermal units' total electricity sales decreased. With wind power utilization efficiency improving the market share and profits of thermal units would both decrease. Therefore, a coordination mechanism should be applied to balance the benefit relationship between thermal and wind power. Table 6 lists the output allocation of thermal power units in the four cases.

Table 6. Output allocation of thermal power units in four cases (MW).

\begin{tabular}{ccccc}
\hline Unit & Case 1 & Case 2 & Case 3 & Case 4 \\
\hline $1 \#$ & 14,400 & 14,400 & 14,400 & 14,400 \\
$2 \#$ & 10,975 & 10,975 & 11,023 & 11,565 \\
$3 \#$ & 5873 & 5873 & 6216 & 6448 \\
$4 \#$ & 3437 & 3437 & 3283 & 2705 \\
$5 \#$ & 2823 & 2823 & 1100 & 600 \\
$6 \#$ & 0 & 0 & 0 & 0 \\
$7 \#$ & 120 & 120 & 0 & 0 \\
$8 \#$ & 0 & 0 & 650 & 0 \\
\hline Total output & 37,629 & 36,672 & 35,718 & 35,196 \\
\hline
\end{tabular}

\subsubsection{System's Economic and Environmental Benefits}

Thermal units' coal consumption and pollutant emission in the four cases are listed in Table 7 (wherein coal cost is $600 \mathrm{Yuan} / \mathrm{t}$ and consume $1 \mathrm{t}$ coal would emit $2.89 \mathrm{t} \mathrm{CO}_{2}$ and $2.05 \mathrm{~kg} \mathrm{SO}$ [43]). Compared with Case 1, thermal units' output and startup-shutdown coal consumption decreased, system's average coal consumption decreased and $\mathrm{CO}_{2}$ and $\mathrm{SO}_{2}$ emission decreased in Case 4 . Therefore, system's power generation cost and pollutant emission cost decreased.

Compared with Case 1, Case 2 decreased coal consumption by $304.5 \mathrm{t}$, which means a decreased coal cost of $18.3 \times 10^{4}$ Yuan. Compared with Case 3, Case 4 could also decrease coal consumption and pollutant emissions. Part of the economic benefits could be used to build a reasonable cost-effective distribution mechanism and provide subsidies for energy storage systems. This could help energy storage 
systems achieve a fiscal balance and promote long-term development of the energy storage industry. Table 7 lists the system coal consumptions and pollutant emissions in the four cases.

Table 7. System coal consumption and pollutant emission in four cases.

\begin{tabular}{ccccccccc}
\hline \multirow{2}{*}{ Cases } & \multicolumn{3}{c}{ Thermal power } & System coal cost & Generation cost \\
$(\mathbf{~}$ & $\begin{array}{c}\text { Output } \\
(\mathbf{M W} \cdot \mathbf{h})\end{array}$ & $\begin{array}{c}\text { Coal } \\
(\mathbf{g} / \mathbf{k W} \cdot \mathbf{h})\end{array}$ & $\begin{array}{c}\text { Start-stop coal } \\
(\mathbf{g} / \mathbf{k W} \cdot \mathbf{h})\end{array}$ & $\begin{array}{c}\mathbf{C O}_{2} \\
(\mathbf{t})\end{array}$ & $\begin{array}{c}\mathbf{S O}_{2} \\
(\mathbf{k g})\end{array}$ \\
\hline Case 1 & 37,629 & 319.08 & 3.15 & 244.70 & 720 & 34,699 & 24,613 \\
Case 2 & 36,672 & 319.10 & 2.81 & 238.49 & 702 & 33,819 & 23,989 \\
Case 3 & 35,718 & 315.96 & 2.63 & 236.95 & 677 & 32,615 & 23,136 \\
Case 4 & 35,196 & 313.17 & 1.75 & 231.03 & 661 & 31,854 & 22,595 \\
\hline
\end{tabular}

For system efficiency, the introduction of TOU price and energy storage systems could decrease abandoned wind power and decrease total coal consumption. The average power generation coal cost would decrease obviously. For environment protection, the introduction of TOU price and energy storage systems could improve system's energy-saving levels. Compared with Case 1, the other three cases decreased coal consumption by $30.45 \mathrm{t}, 720.9 \mathrm{t}$ and $984.3 \mathrm{t}$, respectively, $\mathrm{CO}_{2}$ emission by $907.5 \mathrm{t}$, $2148.3 \mathrm{t}$ and $\mathrm{SO}_{2}$ emission by $2733.4 \mathrm{t}, 624.3 \mathrm{~kg}, 1477.9 \mathrm{~kg}$ and $2017.9 \mathrm{~kg}$.

According to the above analysis, TOU price and energy storage systems could help increase wind power consumption capacity, decrease energy consumption, decrease pollutant emissions and achieve environmental benefits.

\section{Conclusions}

Wind power is intermittent, unstable and its output is anti-load distributed, which hinders its grid connection. Generally wind power can only be effectively utilized in peak load periods, and one cannot avoid abandoned wind power in the flat load and valley load periods. To analyze the influence of ESSs and DRPs on system wind power consumption capacity, an example simulation is made in a 10 units system with $1000 \mathrm{MW}$ wind power and $400 \mathrm{MW}$ energy storage system under four simulation cases. The optimization results show:

1) Energy storage systems and TOU price could influence demand load curve and decrease the peak-valley load ratio. The demand curve would be smoother and system would be able to accept more wind power in the valley load period. Therefore, with the optimization on both the power generation side and load demand side, the system's wind power consumption capacity could be improved.

2) With the influence of energy storage systems and demand response, wind power output increased and thermal units' output decreased. The system's total coal cost would be decreased. However, the thermal power's market share and profits would also be decreased. Therefore, a profits allocation mechanism should be made to ensure the economic benefits of both wind power and thermal power.

3) The introduction of energy storage systems would improve the system's effectiveness and achieve better economic benefits. Therefore, governments could use part of the saved coal cost to provide subsidies for energy storage systems to help the development of related industries. 
4) From the aspect of environment protection, while considering ESSs and DRPs, the system's coal consumption and pollutant emission obviously decreased. This could help the power industry achieve energy-savings.

\section{Acknowledgments}

This paper is supported by the National Science Foundation of China (Grant No: 71273090) and the financial support provided by the CRG Project G-YK60 (RGC Reference: PolyU 5237/11E).

\section{Author Contributions}

Zhongfu Tan and Yihang Song have built the demand response model, energy storage model and power generation scheduling optimization model, Huanhuan Li and Liwei Ju have improved the models and built the scenario simulation and reduction strategy and done the simulation analysis.

\section{Conflicts of Interest}

The authors declare no conflict of interest.

\section{References}

1. Tan, Z.; Wu, E.; Ju, L.; Yi, H.; Shen, S.; Zhang, J. A model for contrastive analysis on risk of income from investment in different wind power resource regions. Power Syst. Technol. 2013, 37, 713-719.

2. Ren, H.; Yao, X.; Zhang, X.; Zhou, Z.; Wang, W. Statistical method for wind farm abandoned wind power. East China Electr. Power 2013, 41, 2148-2152.

3. Jia, W.; Kang, C.; Li, D.; Chen, Z.; Liu, J. Evaluation on capacity of wind power accommodation based on its day-ahead forecasting. Power Syst. Technol. 2012, 36, 69-75.

4. She, X.; Huang, A.Q.; Wang, F.; Burgos, R. Wind energy system with integrated functions of active power transfer, reactive power compensation and voltage conversion. IEEE Trans. Ind. Electron. 2013, 60, 4512-4524.

5. Hou, Y.; Fang, D.; Qi, J.; Li, H.; Niu, W.; Yang, T. Analysis on active power fluctuation characteristics of large-scale grid-connected wind farm and generation scheduling simulation under different capacity power injected from wind farms into power grid. Power Syst. Technol. 2010, 34, 60-66.

6. Bai, J.; Xin, S.; Jia, D.; Chen, L. Study of major questions of wind power digestion and transmission in China. Energy Technol. Econ. 2010, 26, 14-17.

7. Wang, N.; Wang, J.; He, S. Cross-border accommodation method and transmission scheme of Jiuquan wind power. Autom. Electr. Power Syst. 2011, 35, 82-89.

8. Zhu, L.; Chen, N.; Han, H. Key problems and solution of wind power accommodation. Autom. Electr. Power Syst. 2011, 35, 29-34.

9. Xu, W.; Yang, Y.; Li, Z.; Hu, D.; Xia, T.; Kang, C. Participation mode of large-scale Jiuquan wind power farm in Gansu province to electricity market and its utilization scheme. Power Syst. Technol. 2010, 34, 71-77. 
10. Qiao, Y.; Lu, Z.; Xu, F.; Li, K. Performance evaluation method of wind-coal coordinating operation. Autom. Electr. Power Syst. 2013, 37, 1-7.

11. Wang, C.; Qiao, Y.; Lu, Z. A method for determination of spinning reserve in wind-thermal power system considering wind power benefits. Autom. Electr. Power Syst. 2012, 36, 16-21.

12. Zhang, Q.; Feng, Y.; Wang, S. Research on UHV AC transmission of combined electricity generated from wind and thermal. Electr. Power 2012, 6, 1-4.

13. Ault, G.W.; Bell, K.R.W.; Galloway, S.J. Calculation of economic transmission connection capacity for wind power generation. IET Renew. Power Gener. 2007, 1, 61-69.

14. Ahmidi, A.; Guillaud, X.; Besanger, Y. A multilevel approach for optimal participating of wind farms at reactive power balancing in transmission power system. IEEE Syst. J. 2012, 6, 260-269.

15. Li, J.; Shi, P.; Gao, H. China Wind Power Outlook 2010; Haikou Press: Haikou, China, 2010; pp. 87-88. (In Chinese)

16. Zhen, T.; Feng, L.; Wang, S.; Wang, Z.; Fu, X. An optimized wind power dispatching method considering security constraints in the power grid. Autom. Electr. Power Syst. 2010, 34, 71-74.

17. Li, X.; Xing, Z.; Chen, Z.; Chen, Y.; Wang, F.; Luo, J. Design of large clusters of wind power active intelligent control system. Autom. Electr. Power Syst. 2010, 34, 59-63.

18. Yu, D.; Song, S.; Zhang, B.; Han, X. Synergistic dispatch of PEVs charging and wind power in Chinese regional power grids. Autom. Electr. Power Syst. 2011, 35, 24-29.

19. Xu, L.; Yang, G.; Xu, S.; Marra, F. Impacts of electric vehicle charging on distribution networks in Denmark. Autom. Electr. Power Syst. 2011, 35, 18-23.

20. Zhao, J.; Wen, F.; Yang, A.; Xin, J. Impacts of electric vehicles on power systems as well as the associated dispatching and control problem. Autom. Electr. Power Syst. 2011, 35, 2-10.

21. Wang, C. Study on Dispatching and Control Theory of Wind Farm Integrating into Grid. M.S. Thesis, Shandong University, Jinan, China, 2012. (In Chinese)

22. Yin, M.; Wang, C.; Ge, X. Review of economic technical assessment of wind power integration. Proc. CUS-EPSA 2010, 22, 103-108.

23. Cai, X. Research on Available Transfer Capacity of Power System with Wind Power. M.S. Thesis, Harbin Institute of Technology, Harbin, China, 2013. (In Chinese)

24. Rao, J.; Xu, X.; He, Z.; Han, X. Comparison on technical regulations of China and other countries for grid-connection of wind farms. Power Syst. Technol. 2012, 36, 44-49.

25. Dong, C.; Pei, Z.; Huang, Y. Comparative study of integrating technique for wind power between China and Germany. Electr. Power 2013, 46, 83-89.

26. Gao, Z.; Teng, X.; Zhang, X. Solution of active power dispatch and control scheme for interconnected power grids with large-scale wind power integration. Autom. Electr. Power Syst. 2010, 34, 37-42.

27. $\mathrm{Li}, \mathrm{M}$. Research and practice of wind power dispatch based on international advanced experience. Electr. Power 2012, 45, 1-6.

28. Chen, X.; Zhang, C.; Qi, Z. DSM solution measures and its feasibility in our country. Power Demand Side Manag. 2004, 5, 7-9.

29. Boukhezzar, B.; Siguerdidjane, H.; Maureen, H.M. Nonlinear control of variable-speed wind turbines for generator torque limiting and power optimization. ASME J. Sol. Energy Eng. 2006, $128,516-530$. 
30. Sun, H.; Peng, C.; Yi, H. Multi-objective stochastic dispatch of power system with wind farms. Electr. Power Autom. Equip. 2009, 29, 18-22.

31. Roy, S. Market constrained optimal planning for wind energy conversion systems over multiple installation sites. IEEE Trans. Energy Convers. 2002, 17, 124-129.

32. Liu, W.; Jiang, C.; Zhang, J.; Wang, X.; Yu, L.; Liu, D. A multistage reliability model of wind turbines for sequential Monte Carlo simulation. Power Syst. Protect. Control 2013, 41, 73-80.

33. Yu, H.; Chung, C.; Wong, K.; Zhang, J. A probabilistic load flow calculation method with Latin hypercube sampling. Autom. Electr. Power Syst. 2009, 33, 32-35.

34. Yu, H.; Chung, C.Y.; Wong, K.P. Probabilistic load flow evaluation with hybrid Latin hypercube sampling and cholesky decomposition. IEEE Trans. Energy Convers. 2009, 24, 661-667.

35. Stein, M. Sample size requirement for Monte Carlo-simulations using Latin hypercube sampling. Technimetrics 1989, 29, 143-151.

36. Heitsch, H.; Römisch, W. Scenario reduction algorithms in stochastic programming. Comput. Optim. Appl. 2003, 24, 187-206.

37. Römisch, W. Scenario Reduction Techniques in Stochastic Programming; Humboldt-University: Berlin, Germany, 2009.

38. Dupacova, J.; Growe-Kuska, N.; Römisch, W. Scenario Reduction in Stochastic Programming: An Approach Using Probability Metrics; Springer-Verlag: New York, NY, USA, 2003.

39. Growe-Kuska, N.; Dupacova, J.; Römisch, W. Scenario reduction and scenario tree construction for power management problems. In Proceedings of the IEEE Bologna Power Technology Conference, Bologna, Italy, 23-26 June 2003.

40. Heich, H.; Römisch, W. A note on scenario reduction for two-stage stochastic programs. Oper. Res. Lett. 2007, 35, 731-738.

41. Xu, F.; Yao, J.; Gen, J.; Yang, Z. Modeling and analysis of unit I/O characteristics based on mixed-integer programming. Autom. Electr. Power Syst. 2010, 34, 45-50.

42. Carrion, M.; Arroyo, J.M. A computationally efficient mixed-integer linear formulation for the thermal unit commitment problem. IEEE Trans. Power Syst. 2006, 21, 1371-1378.

43. Hu, Z.; Song, Y.; Xu, Z.; Luo, Z.; Zhan, K.; Jia, L. Impacts and utilization of electric vehicles integration into power systems. Proc. CSEE 2012, 32, 1-10.

(C) 2014 by the authors; licensee MDPI, Basel, Switzerland. This article is an open access article distributed under the terms and conditions of the Creative Commons Attribution license (http://creativecommons.org/licenses/by/4.0/). 